\title{
PENGGUNAAN TEKNOLOGI IVR UNTUK MENINGKATKAN KINERJA DOSEN PRAKTIKUM
}

\author{
Ashadi Kurniawan \\ Jurusan Teknik Telekomunikasi, Departemen Teknik Elektro, \\ Politeknik Elektronika Negeri Surabaya \\ Jl. Raya ITS - Kampus PENS Sukolilo, Surabaya, 60111 \\ Email:Wawan@staff.pens.ac.id
}

\begin{abstract}
ABSTRAK
Tenaga pendidik (dosen) memiliki aktifitas selain mengajar juga melakukan Penelitian, membimbing mahasiswa yang sedang Tugas Akhir dan ada yang mendapatkan jabatan struktural. Untuk membantu ketepatan pelaksanaan mengajarnya, maka dibuat suatu sistem pengingat waktu mengajar dosen secara otomatis, dimana pada sistem ini digunakan database yang terhubung dengan sistem Interactive Voice Respons (IVR). Kinerja sistem ini diuji berdasarkan ketepatan waktu dan ketepatan nomor ekstensi ruangan dosen yang di hubungi. Berdasarkan hasil pengujian yang dilakukan, sistem dapat menghubungi nomor ekstensi ruangan dosen yang terdaftar pada database. Sedangkan delay panggilan dari sistem ke nomor ekstensi ruangan dosen rata rata mencapai 5 detik. Sehingga dengan adanya sistem yang dibuat, dapat membantu dan memperlancar proses belajar mengajar khususnya untuk mata kuliah praktikum dan juga meningkatkan kinerja dosen Praktikum.
\end{abstract}

Kata kunci: Interactive Voice Respons, database, otomatis, delay

\section{IVR TECHNOLOGY FOR INCREASING LECTURER'S PERFORMANCE}

\begin{abstract}
Lecturers have activities besides teaching as well as conducting research, guiding students who are in the final project, and some who get structural positions. To assist with the accuracy of the teaching process, a system to automatically remind lecturers is made, where a database is connected to the Interactive Voice Response (IVR) system. The performance of this system is tested based on the timeliness and accuracy of the lecturer room extension number contacted. Based on the results of the tests performed, the system can contact the extension number of the lecturer room registered in the database. While the delay of calls from the system to the extension number of the lecturer room reaches 5 seconds on average. So that with the system being created, it can help and expedite the teaching and learning process especially for practicum courses and also improve the performance of Practicum lecturers.
\end{abstract}

Keywords: Interactive Voice Response, Database, Automatic, Delay.

\section{PENDAHULUAN}

Sebagai seorang Pranata Laboratorium Pendidikan, dituntut untuk selalu dapat memantau segala aktivitas didalam laboratorium baik itu pelaksanaan praktikum dan penggunaan peralatan. Dalam hal pelaksanaan proses belajar mengajar khususnya untuk mata kuliah praktikum, seorang pranata laboratorium dituntut untuk selalu menjaga kelancaran proses belajar mengajar, terutama diruang laboratorium.
Aktivitas dosen selain mengajar sangat banyak, antara lain membimbing mahasiswa, melakukan penelitian dan ada yang mendapat amanah untuk menjadi pejabat struktural. Pada saat mata kuliah praktikum terkadang dosen datang terlambat dikarenakan beberapa faktor diatas.

Oleh karena itu, untuk membantu ketepatan pelaksanaan mengajarnya, maka dibuat suatu sistem aplikasi Interactive Voice Response (IVR). Server yang digunakan 
pada layanan ini bersifat aktif, dimana server memutarkan suara rekaman untuk mengingatkan waktu mengajar kepada dosen yang ada didalam database sistem. aplikasi sistem layanan ini seperti pengingat (reminder), yang akan selalu mengingatkan dosen kapan waktu jadwal mengajarnya.

Sistem Pengingat (Reminder) akan membunyikan suara berupa file rekaman dalam waktu tertentu sesuai jadwal yang sudah diatur dan disimpan kedalam database. Adapun data yang akan disampaikan oleh sistem adalah sebuah voice yang sudah disimpan di database sebelumnya.

Pembuatan Aplikasi ini mempunyai fungsi sebagai membantu dosen untuk mengingatkan waktu Jam mengajar sehingga dapat memperlancar proses belajar Mengajar sehingga dapat meningkatkan kinerja khususnya ketepatan kedatangan dosen disaat mengajar matakuliah praktikum.

\section{METODOLOGI}

Pengerjaan sistem yang dilakukan antara lain :

a. Studi literatur dan persiapan perancangan. Studi literatur merupakan keharusan seseorang sebelum terjun kedalam. Sistem, karena didalam sistem nanti pasti akan terdapat berbagai macam kemungkinan yang terjadi baik permasalahan internal maupun eksternal. Dalam proses perancangan dan pembuatan diperlukan persiapan agar program yang dikerjakan memiliki gambaran yang sangat jelas, baik gambaran mengenai masalah dan parameter parameter yang digunakan hingga gambaran luaran yang akan dihasilkan dimana persipan tersebut meliputi pemecahan masalah yang diangkat hingga konsultasi dengan para calon pemakai.

b. Perancangan sistem. Setelah mempelajari literatur dan materi materi yang tersedia, dimulailah perencanaan sistem dan pembuatan aplikasinya. Secara umum perancangan sistem dijelaskan pada Gambar 2. Prosedur sistem reminder yang dilakukan dalam penelitian ini adalah sebagai berikut :

- Server mencocokkan waktu yang tersimpan didalam database dengan waktu yang berjalan didalam server.

- Ketika waktu pada server dan yang tersimpan di database menunjukkan waktu yang sama, maka server akan melihat data nomor telepon pada baris yang sama dengan baris jam di tabel database.

- Selanjutnya, server akan melakukan panggilan ke nomor telepon dosen yang tersimpan didalam database.

Jika nomor yang dihubungi sedang tidak sibuk dan dosen yang bersangkutan mengangkat telepon (off-hook), maka dosen tersebut akan mendapatkan reminder berupa suara rekaman yang berisi informasi pengingat waktu mengajar mata kuliah praktikum.

Namun apabila nomor telepon dosen yang dihubungi sedang sibuk (busy), maka pada periode waktu tertentu server akan menghubungi kembali ke nomor dosen tersebut. Apabila panggilan tidak diangkat hingga beberapa kali maka dosen dianggap tidak bisa mengajar mata kuliah praktikum. Untuk blok diagram IVR bisa dilihat pada Gambar 1.

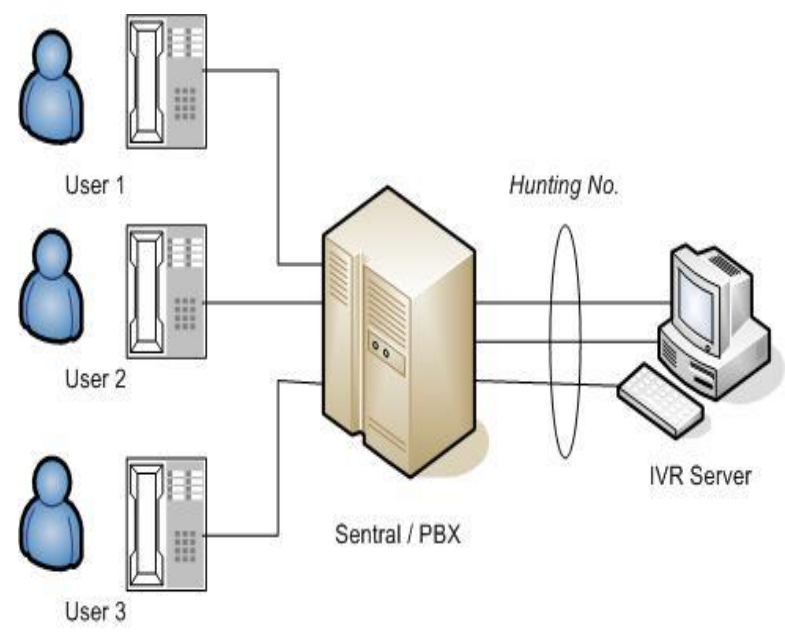

Gambar 1. Blok Diagram Sistem IVR

(sumber: Modul Praktikum Dasar Jaringan Telephoni PENS 2012 ) 
Tabel 1. Daftar Kata yang Akan Direkam (Sumber : data penelitian)

\begin{tabular}{ccc}
\hline No & Nama File & Kalimat \\
\hline $\mathbf{1 .}$ & pagi.wav & Selamat pagi \\
\hline $\mathbf{2 .}$ & siang.wav & Selamat siang \\
\hline $\mathbf{3 .}$ & prima.wav & Bu Prima \\
\hline $\mathbf{4 .}$ & mike.wav & Bu Mike \\
\hline $\mathbf{5 .}$ & aries.wav & Pak Aries \\
\hline $\mathbf{6 .}$ & zen.wav & Pak Zen \\
\hline $\mathbf{7 .}$ & 2d3ta.wav & Kelas 2D3TA \\
\hline $\mathbf{8 .}$ & 2d3tb.wav & Kelas 2D3TB \\
\hline $\mathbf{9 .}$ & 3d4ta.wav & Kelas 3D4TA \\
\hline $\mathbf{1 0}$. & 3d4tb.wav & Kelas 3D4TB \\
\hline $\mathbf{1 1 .}$ & 4d4ta.wav & Kelas 4D4TA \\
\hline $\mathbf{1 2 .}$ & 4d4tb.wav & Kelas 4D4TB \\
\hline $\mathbf{1 3}$. & dastel.wav & Dasar Telepon \\
\hline $\mathbf{1 4}$. & mod.wav & Modulasi \\
\hline $\mathbf{1 5}$. & jartel.wav & Jaringan Telepon \\
\hline $\mathbf{1 6 .}$ & coding.wav & Coding \\
\hline $\mathbf{1 7 .}$ & jam1.wav & Jam pertama pukul 8 pagi \\
\hline $\mathbf{1 8}$. & Jam2.wav & Jam kedua pukul setengah 11 siang \\
\hline $\mathbf{1 9}$. & remind.wav & Jangan lupa mengajar mata kuliah \\
\hline $\mathbf{2 0 .}$ & trims.wav & Terimakasih \\
\hline & & \\
\hline
\end{tabular}
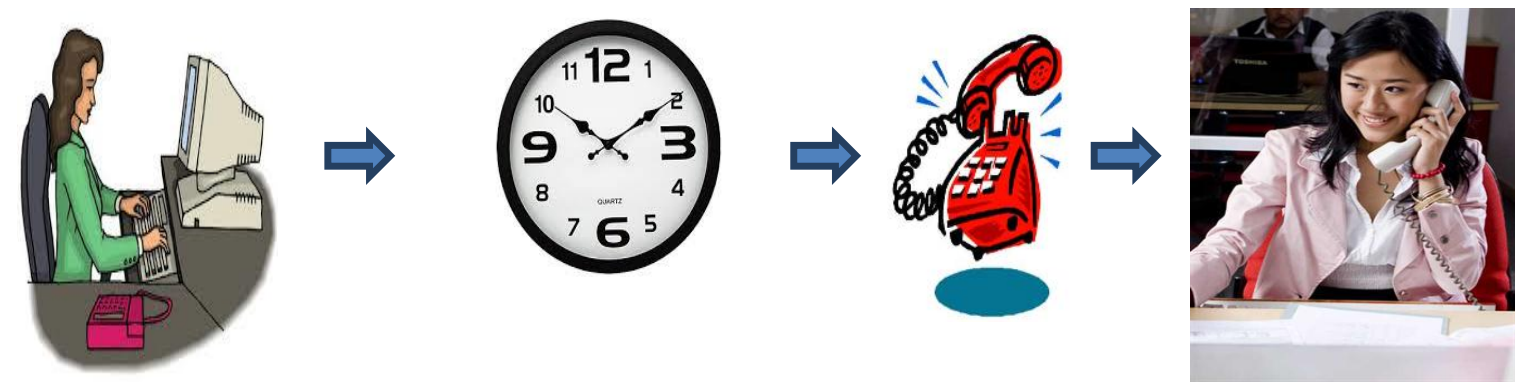

Gambar 2. Perancangan Sistem

c. Pengujian dan Evaluasi. Pengujian ini meliputi "trial dan error" dan uji lapangan. Trial Error dimaksudkan untuk menguji coba apakah alat ini berfungsi dengan baik dan sesuai target atau masih memerlukan tahap "troubleshooting" untuk masalah yang ditemui. Tahap selanjutnya adalah pengujian dilapangan untuk mendapatkan hasil data sebagai bahan pembuatan laporan dan evaluasi secara keseluruhan. Adapun flowchart sistem aplikasi ini adalah sebagai berikut.

\section{HASIL DAN PEMBAHASAN}

Setelah proses desain tabel dan database sudah dibuat, maka tampilan tabel database nya terdapat pada Tabel 2. Pada aplikasi ini dibuat database jadwal pembelajaran dosen yang kemudian diinputkan rekaman sebagai IVR outbound nya dan ditambahkan program yang berbasis $C++$ yang terdapat web sebagai outputnya. Sehingga IVR akan melakukan sinkronisasi waktu antara waktu server yang ada di web dengan remainder pada program. 


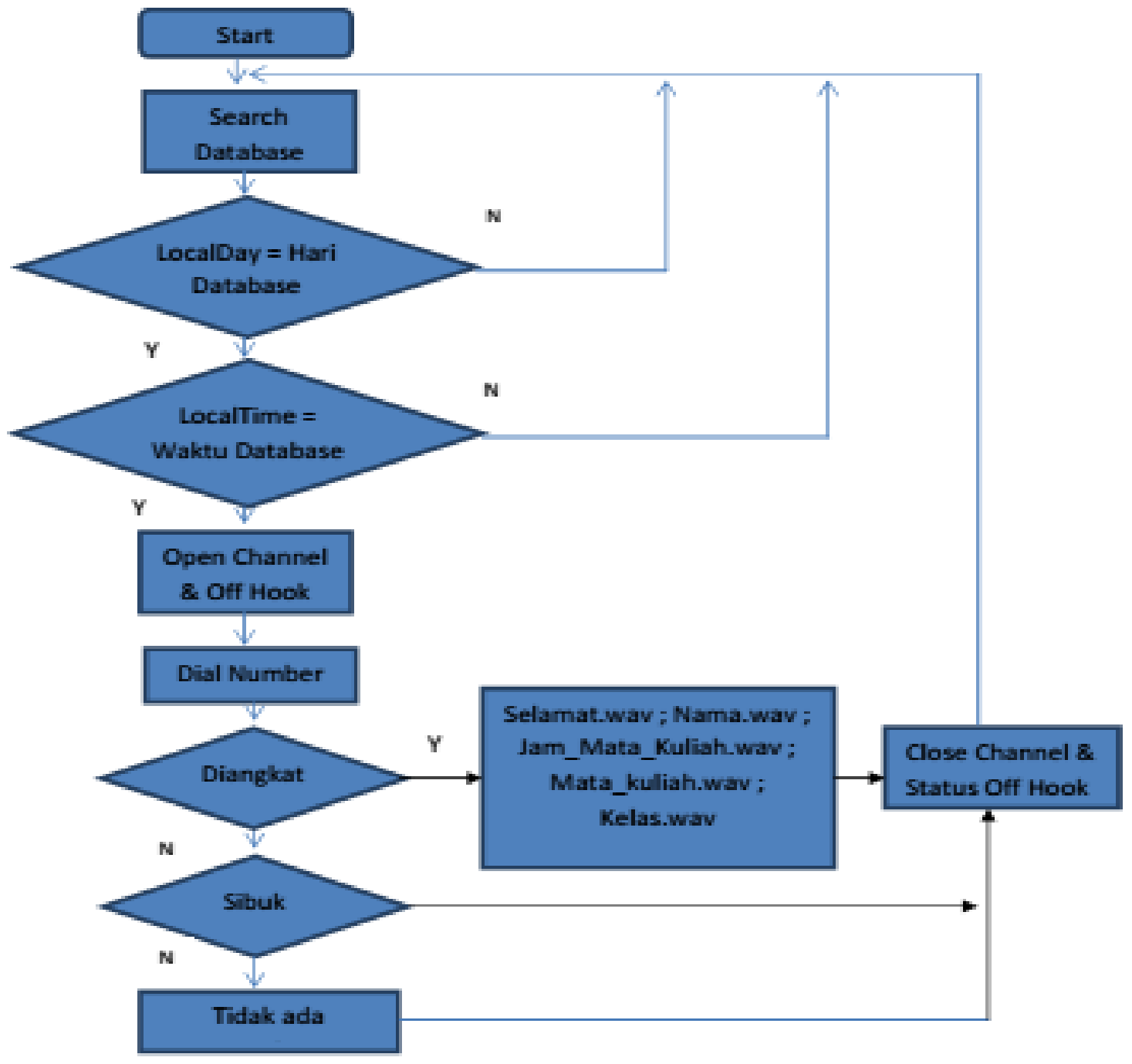

Gambar 3. Flowchart Sistem Aplikasi

Sistem Remainder ini secara umum disetting akan mengulang program secara terus menerus sampai waktu yang telah ditentukan pada database sesuai atau sama dengan Local Time atau pada Web nya. Ketika waktu sudah sama maka program akan membuka channel dan akan tersambung diteleponnya. Ketika dosen mengangkat telepon maka secara otomatis akan terdengar suara rekaman.wav yang telah dibuat. Setelah telepon ditutup atau dalam keadaan on hook kembali maka terus me-looping programmnya hingga waktu yang telah kita setting pada database sesuai dengan waktu local time web-nya berjalan.
Pada penelitian ini ditambahkan program dengan (Sleep (60000); di beberapa letak. Untuk syntax sleep sendiri berfungsi sebagai delay atau jeda dengan sleep (60000) untuk delay pengecekan remainder $(60000$ yang berarti $=1$ menit remainder). Maka program akan mengecek waktu / menyamakan waktu dengan database dengan local time setiap 1 menit sekali. 
Tabel 2. Hasil Pengisian Database (sumber: data penelitian)

\begin{tabular}{c|c|c|c|c|c|c|c|c}
\hline ID & Nama & Mata_Kuliah & Kelas & $\begin{array}{c}\text { Jam } \\
\text { Mata } \\
\text { Kuliah }\end{array}$ & $\begin{array}{c}\text { Nomor } \\
\text { Telepon }\end{array}$ & Hari & Jam & Menit \\
\hline 1. & Prima.wav & Jartel.wav & 3D4TA.wav & $1 . w a v$ & 1503 & 1 & 07 & 45 \\
2. & Prima.wav & Dastel.wav & 2D3TB.wav & 2.wav & 1503 & 2 & 10 & 15 \\
3. & Aries.wav & Modulasi.wav & 3D4TA.wav & 2.wav & 1502 & 1 & 10 & 15 \\
4. & Aries.wav & Coding.wav & 4D4TA.wav & $1 . w a v$ & 1502 & 3 & 07 & 45 \\
5. & Mike.wav & Dastel.wav & 2D3TA.wav & 1.wav & 1504 & 4 & 07 & 45 \\
6. & Mike.wav & Jartel.wav & 3D4TB.wav & 1.wav & 1504 & 5 & 07 & 45 \\
7. & Zen.wav & Modulasi.wav & 3D4TB.wav & 2.wav & 1501 & 3 & 10 & 15 \\
8. & Zen.wav & Coding.wav & 4D4TB.wav & 2.wav & 1501 & 5 & 10 & 15 \\
\hline
\end{tabular}

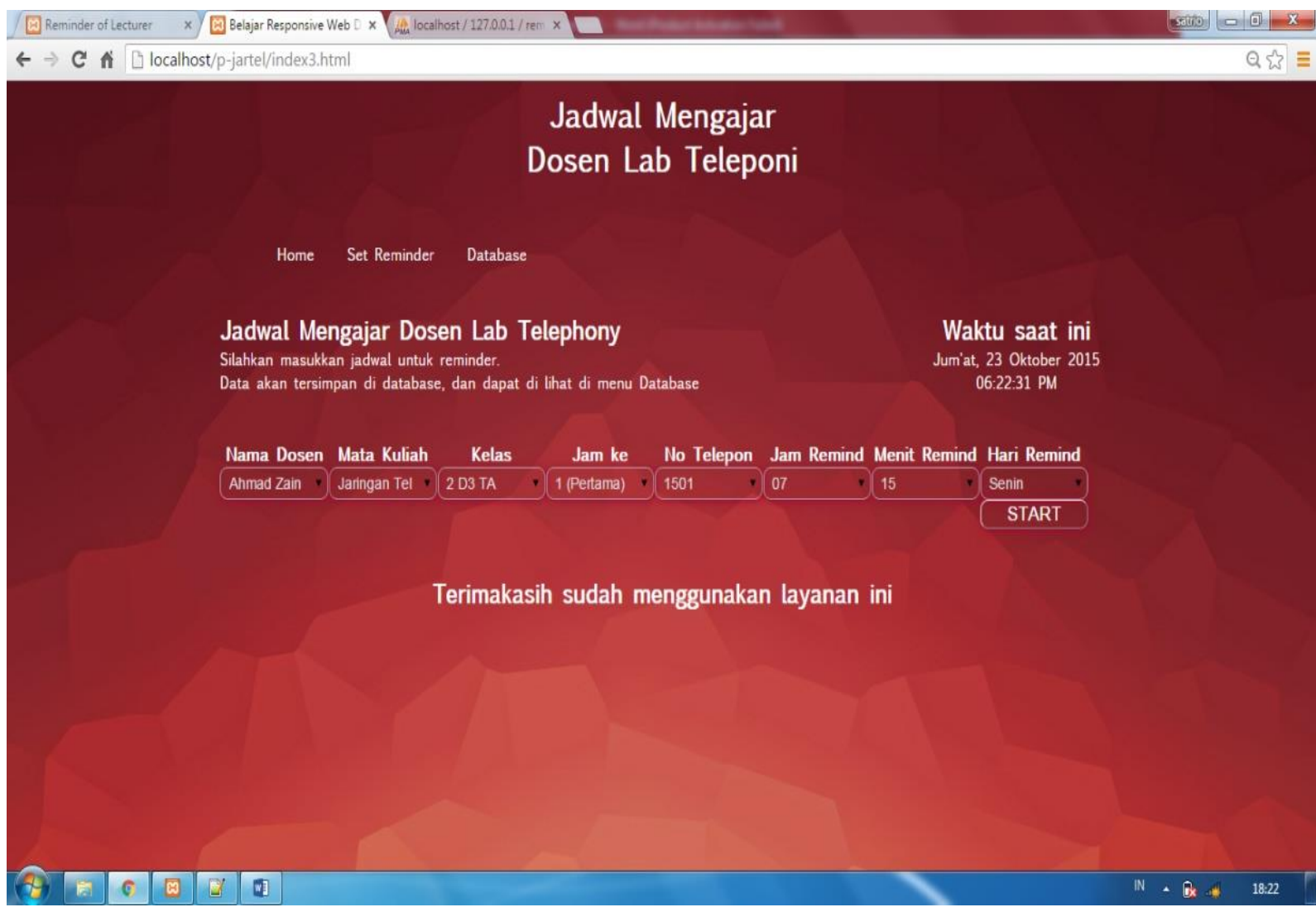

Gambar 4. Tampilan Web Databse

Pada Aplikasi ini ini langkah pertama yang dilakukan adalah membuat database jadwal pembelajaran dosen, setelah menginputkan hasil rekaman sesuai perintah yang diinginkan sebagai IVR outbound nya. Kemudian menambahkan program yang berbasiis $C++$ untuk menjalankan perintahnya. hasil output aplikasi pada WEB, sehingga akan terjadi proses pengsingkronisasian waktu antara waktu pada server dengan yang ada pada WEB dengan reminder pada WEB. Pada aplikasi ini ada perintah sleep. Pada syntax sleep yang pertama yaitu terletak pada proses untuk mendeteksi local time kemudian ditampilkan pada jendela command prompt 
sehingga dapat dilihat pada program sebagai berikut ini.

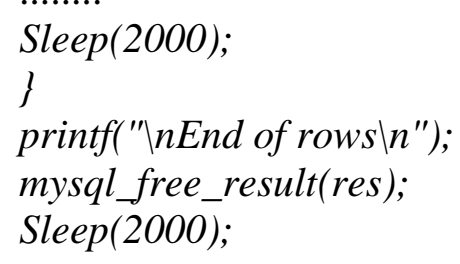

Pada proses sebelumnya adalah mendeteksi local time untuk hari, jam dan menit yang kemudian ditampilkan secara real time pada command prompt, selanjutnya adalah proses delay yaitu waktu tunda untuk menampilkan local time kembali dan ditampilkan pada command prompt. Ketika dihitung waktu untuk syntax sleep (2000), didapatkan waktu tunda selama 4 detik. Kemudian syntax sleep (2000) diubah menjadi sleep (1000) dan ketika program dijalankan, akan menampilkan local time secara terus menerus dengan delay atau waktu tunda selama 2 detik, setelah itu syntax sleep kedua yang terletak setelah layanan sudah selesai memainkan suara. Dapat dilihat pada program berikut ini.

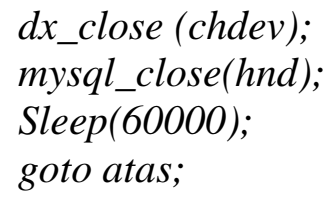

Maka setelah program selesai memainkan file suara, lalu sambungan akan diputus kembali dan akan terjadi delay selama 42 detik, waktu tunda itu didapatkan pada syntax sleep (60000), sehingga setelah 42 detik, maka akan kembali ke label atas dan memulai mendeteksi local time kembali.
Kemudian untuk mendeteksi panggilan kedua, jika sudah sama maka open chanel dan off hook lalu memanggil nomor telepon yang ada di database.

Server mencocokkan waktu yang tersimpan didalam database dengan waktu yang berjalan didalam server. Ketika waktu pada server dan yang tersimpan di database menunjukkan waktu yang sama, maka server akan melihat data nomor telepon pada baris yang sama dengan baris jam di tabel database. Selanjutnya, server akan melakukan panggilan ke nomor telepon dosen yang tersimpan didalam database.

Berdasarkan hasil pengujian yang dilakukan, sistem dapat menghubungi nomor ekstensi ruangan dosen yang terdaftar pada database. Sedangkan delay panggilan dari sistem ke nomor ekstensi ruangan dosen rata rata mencapai 5 detik. Untuk melihat efektifitas sistem pengingat ini, maka dilakukan pengambilan data dilaboratorium dengan sampling sebanyak 5 orang dosen dengan mengamati waktu kedatangan dosen tersebut saat mengajar matakuliah praktikum. Setelah dilakukan pengamatan, maka didapatkan data seperti yang ada di Tabel 3 dan Tabel 4.

Dari data Tabel 3 dan Tabel 4 dapat dihitung, persentase ketepatan dosen datang saat praktikum sebesar $80 \%$ setelah menggunakan alat pengingat waktu mengajar secara otomatis. Sehingga dapat dikatakan bahwa alat pengingat waktu mengajar ini bisa memperbaiki dan meningkatkan kinerja kedatangan dosen disaat mengajar mata kuliah praktikum. Di Tabel 3, setelah mengambil sampling sebanyak 10 buah data, maka dapat dihitung persentase ketepatan dosen disaat mengajar mata kuliah praktikum sebesar $40 \%$. 
Tabel 3. Kedatangan Dosen Sebelum Ada Alat Pengingat Otomatis

\begin{tabular}{|c|c|c|c|c|c|}
\hline No & $\begin{array}{l}\text { Nama } \\
\text { Dosen }\end{array}$ & $\begin{array}{c}\text { Mata } \\
\text { KuliahPraktikum }\end{array}$ & $\begin{array}{c}\text { Waktu } \\
\text { Praktikum }\end{array}$ & $\begin{array}{c}\text { Kedatangan } \\
\text { Dosen }\end{array}$ & Keterangan \\
\hline 1 & $\begin{array}{l}\text { Ibu Mike } \\
\text { Yuliana }\end{array}$ & Jartel & 08.00 & 08.10 & Terlambat \\
\hline 2 & $\begin{array}{l}\text { IbuMike } \\
\text { Yuliana }\end{array}$ & Pemrograman & 10.30 & 10.40 & Terlambat \\
\hline 3 & $\begin{array}{l}\text { Ibu Prima } \\
\text { Kristalina }\end{array}$ & Jartel & 10.30 & 10.30 & Tepat \\
\hline 4 & $\begin{array}{l}\text { Ibu Prima } \\
\text { Kristalina }\end{array}$ & Dastel & 14.00 & 14.30 & Terlambat \\
\hline 5 & BapakAmran & Pemrograman & 08.00 & 08.10 & Terlambat \\
\hline 6 & BapakAmran & Pemrograman & 10.30 & 10.30 & Tepat \\
\hline 7 & Bapak Aries & Modulasi & 08.00 & 08.20 & Terlambat \\
\hline 8 & Bapak Aries & Modulasi & 14.00 & 13.50 & Tepat \\
\hline 9 & IbuRenni & Pemrograman & 08.00 & 08.40 & Terlambat \\
\hline 10 & IbuRenni & Pemrograman & 10.30 & 10.30 & Tepat \\
\hline
\end{tabular}

Tabel 4. Kedatangan Dosen Sesudah Memakai Alat Pengingat Otomatis

\begin{tabular}{|c|c|c|c|c|c|}
\hline No & $\begin{array}{l}\text { Nama } \\
\text { Dosen }\end{array}$ & $\begin{array}{c}\text { Mata Kuliah } \\
\text { Praktikum }\end{array}$ & $\begin{array}{c}\text { Waktu } \\
\text { Praktikum }\end{array}$ & $\begin{array}{c}\text { Kedatangan } \\
\text { Dosen }\end{array}$ & Keterangan \\
\hline 1 & $\begin{array}{l}\text { Ibu Mike } \\
\text { Yuliana }\end{array}$ & Jartel & 08.00 & 08.10 & Terlambat \\
\hline 2 & $\begin{array}{l}\text { Ibu Mike } \\
\text { Yuliana }\end{array}$ & Pemrograman & 10.30 & 10.30 & Terlambat \\
\hline 3 & $\begin{array}{l}\text { Ibu Prima } \\
\text { Kristalina }\end{array}$ & Jartel & 10.30 & 10.30 & Tepat \\
\hline 4 & $\begin{array}{l}\text { Ibu Prima } \\
\text { Kristalina }\end{array}$ & Dastel & 14.00 & 14.00 & Terlambat \\
\hline 5 & BapakAmran & Pemrograman & 08.00 & 08.10 & Terlambat \\
\hline 6 & BapakAmran & Pemrograman & 10.30 & 10.30 & Tepat \\
\hline 7 & Bapak Aries & Modulasi & 08.00 & 08.00 & Terlambat \\
\hline 8 & Bapak Aries & Modulasi & 14.00 & 14.00 & Tepat \\
\hline 9 & IbuRenni & Pemrograman & 08.00 & 08.00 & Terlambat \\
\hline 10 & IbuRenni & Pemrograman & 10.30 & 10.30 & Tepat \\
\hline
\end{tabular}

\section{KESIMPULAN}

Dari hasil pembuatan aplikasi dan analisa data maka dapat disimpulkan bahwa:

- Program harus bebas dari error / kesalahan untuk menjalankan program dan pembuatan web-nya harus benar agar layanan remainder dapat berjalan dengan baik.

- Pemanggilan banyak user secara bersama - sama (mem-broadcast) dapat dilakukan di project ini, karena kita tambahkan waktu tunda dalam program dan disini kita juga tidak menggunakan kanal.

- Syntax sleep kita gunakan untuk waktu tunda didalam proes menjalankan program dan dapat kita atur waktu tunda tersebut, sehingga dapat kita gunakan dalam waktu tunda antara panggilan user pertama dan selanjutnya.

- Kinerja kedatangan dosen Praktikum meningkat dengan adanya sistem pengingat waktu mengajar otomatis ini. 


\section{DAFTAR PUSTAKA}

Interactive Voice Response (IVR) (2007).

Sejarah dan Masa Depan. http://www.asteindo-tehnology.com.

Ismar W. (2 014, 08 Desember ) Apa itu Interractive Voice Response? http://ismarw.blogspot.com/2014/12/ap a-itu-inveractive-voice-responseivr.html.

Linksys (2017). VoIP Konfigurasi Linksys SPA400 dengan Asterisk [online]. http://opensource.telkomspeedy.com.

Mike Yuliana (2011). Pemrograman Instalasi dasar IVR, Modul Praktikum Jaringan telephoni, PENS.

Miruna Mitranescu (2015, 20 Juni ) What is Interactive Voice Response https://aircall.io/blog/callcenter/interactive-voice-responsel.

Muhammad Wahid (2013, 27 Juni). Apa itu IVR? http://mwahid-

21.blogspot.com/2013/06/ivr-apaitu.html.

Noris, Shandi (2009) Rancang Bangun Implementasi Teknologi VoIP pada Aplikasi Jaringan IP Phone Melalui Jaringan Internet yang Berbeda. skripsi mahasiswa Sekolah Tinggi Manajemen Informatika dan Komputer Jakarta (STI\&K).

Parateum (2018) New release of our IVR Flow builder https://www.comsys.net/news/115/113/ New-release-of-our-IVR-Flowbuilder/d,News.html.

Prima Kristalina (2012). Pemrograman IVR Outbond, Modul Praktikum Dasar Jaringan Telephoni PENS.

Twilio (2016). Build a scalable IVR System to reduce operation costs and increase customer Satisfaction https://www.twilio.com/solutions/ivr? $=a w \cdot d s$. 